Editorial

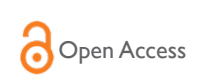

CrossMark

\title{
Substance use and early psychosis
}

\section{Editorial}

As I see the cannabis debate play out in the US, I am thinking to myself as an early intervention in psychosis psychiatrist, what are the implications of this policy to adolescent psychiatry.

Teenage Cannabis use was highest in Canada, according to a recent study, what is the implication of these numbers to adolescent psychiatry. ${ }^{1}$ There has been strong and conclusive evidence the link between cannabis use and psychosis. ${ }^{2}$ Moreover, the history of mental illness puts children and adolescents at increased risk of early psychosis symptoms as well as conversion to florid psychosis in the future.

The other side of this equation is individual rights and freedoms; charter protects the right of an individual. In Canada one cannot involuntary hospitalize someone for addictions alone, and there is a reason for that. ${ }^{3}$ It is important to weight both sides of this situation, however, I do have difficulty sleeping at night thinking about the future for our children. I have seen cases of long term cannabis abuse and subsequent conversion to psychosis that is not ameliorated by subsequent abstinence. Are children old enough to understand the implications of their actions, can they adequately evaluate the consequences of their actions. I will always support individual right and freedoms.

I am sure this is an issue that all child psychiatrist as well as all mental health clinicians struggle with. I hope we can continue to educate the adolescent populations on the potential risk of cannabis use and its implications to mental health. As such this subpopulation can make informed choices about their actions. As an adolescent psychiatrist, I know teenagers are well connected and are willing to do their own research on this topic and I have seen changes in behavior as a result. I feel more psycho-education, particularly in the pre-teen years can be significantly helpful. As cannabis moves toward more
Volume I Issue I - 2015

A Rajeevan Rasasingham

Department of Psychiatry, University of Toronto, Canada

Correspondence: A Rajeevan Rasasingham, Assistant Professor, Department of Psychiatry, University of Toronto, Toronto, Ontario, Canada, Email rrasasingham@hrh.ca

Received: May 02, 2015 | Published: May II, 2015

legalization and acceptance in the general society, I hope that psychoeducation increases and maybe teenage use may be experimental and not an addictions issue. As well, adolescents with family history of mental illness or history of mental illness themselves will be careful when starting or experimenting with this substance.

\section{Acknowledgements}

None.

\section{Conflict of interest}

The author declares no conflict of interest.

\section{References}

1. Peter A. Child Wellbeing in Rich Countries: A Comparative Overview. Innocent Report Card 11. Unicef office of Research. Italy, 2013. 24 p.

2. van Os J, Bak M, Hanssen M, et al. Cannabis use and psychosis: a longitudinal population-based Study. Am J Epidemiol. 2002;156(4):319327.

3. http://www.oha.com/currentissues/keyinitiatives/mentalhealth/pages/ mentalhealthandthelaw.aspx 